\title{
Functional movement disorders in a patient with COVID-19
}

\author{
Daniele Piscitelli ${ }^{1,2}$ (i) Cecilia Perin ${ }^{1} \cdot$ Lucio Tremolizzo $^{1} \cdot$ Federica Peroni $^{1} \cdot$ Cesare Giuseppe Cerri $^{1}$. \\ Cesare Maria Cornaggia ${ }^{1}$
}

Received: 14 June 2020 / Accepted: 8 July 2020 / Published online: 14 July 2020

(C) Fondazione Società Italiana di Neurologia 2020

\section{Dear Editor-in-Chief,}

Evidence suggests that the severe-acute respiratory syndrome coronavirus-2 (SARS-CoV-2) responsible for the new coronavirus disease (COVID-19) pandemic is leading to an increased onset of psychiatric events [1]. New cases of mental disorders have been reported in otherwise healthy individuals, such as reactive psychoses, anxiety, insomnia, panic, and obsessive-compulsive disorders [2, 3]. Many people who previously coped well are after COVID-19 less able to cope because of the multiple stressors generated by the pandemic.

"Fear" may be the main cause of such psychiatric events, whether in relation to the onset of SARS-CoV-2 symptoms or to the lockdown. We report the case of a 39-year-old woman, inhome nurse, of normal social well-being with no history of somatoform or other psychiatric disorder or traumas, who developed, with SARS-CoV-2 infection, functional tremors. A signed release from the patient authorizing publication was obtained.

\section{Case report}

The subject, on March 5, 2020, began experiencing fever ( $38^{\circ} \mathrm{C}$ ), loss of smell, muscle pain, and gastrointestinal symptoms. On March 22, nasopharyngeal swab was positive for SARS-CoV-2. The patient started the self-isolation quarantine period. While in quarantine, two of her housemates also tested positive for SARS-CoV-2. After 7 days with mild SARS-

Daniele Piscitelli

daniele.piscitelli@mcgill.ca; danypisci@yahoo.it

1 School of Medicine and Surgery, University of Milano-Bicocca, Milan, Italy

2 School of Physical and Occupational Therapy, McGill University, 3654 Promenade Sir-William-Osler, Montreal, QC H3G 1Y5, Canada
CoV-2 symptoms, she started to develop a lower limb tremor with variable frequency and amplitude. No tremor was shown in the upper limbs and in the cephalic district. She presented abnormal movements while sitting (e.g., lower limb twisted movements), walking (e.g., ataxic gait), or at rest (e.g., jerky movements in supine position). On March 30, she was admitted to the Emergency Department treated with benzodiazepines without significant improvement. On April 1, she was referred to the Neurological Department, where no neurological impairments were found, i.e., negative for Babinski responses and sensory tests, normal muscle tone, and deep tendon reflexes and coordination (finger-to-nose test, rapid alternating finger movements, and heel-to-shin test). Lower limb tremors prevented gait assessment. On April 10, she was discharged with a diagnosis suspected of functional disorder.

By April 17, the tremor and disrupted movements had increased. She underwent a brain and spine MRI with and without gadolinium contrast. No abnormal findings were reported. The patient was also referred to a neurologist that prescribed additional serum tests. Blood tests were negative for Borrelia burgdorferi, treponema pallidum, HIV, antiphospholipid antibody syndrome, thyroid disease, brain natriuretic-peptide, and ceruloplasmin.

She then tested negative twice for SARS-CoV-2 on May 5 and May 7 by nasopharyngeal swab. In the following days, tremor intensity and frequency decreased and the patient was able to walk with a mild aid. A neurological examination on May 13 confirmed the clinical characteristic of functional movement disorder [4-6]. In particular, she showed entrainment phenomenon and effect of distractibility on the intensity of movement disorder. Clinically, the coactivation of agonist and antagonist muscles was perceived while moving the lower limbs passively. Somatosensory evoked potentials from the peroneal nerve were normal. In the following psychiatric evaluation, the patient felt comfortable and willing towards the interview without presenting any awareness of symptoms, excluding a Munchausen syndrome. 


\section{Discussion}

The significance of this case is that an entirely new psychiatric symptomatology resembling a neurological one was exhibited by a patient who, before SARS-CoV-2 infection, had no history of psychiatric/neurologic events. Indeed, the symptomatology (i.e., tremors and abnormal movements) may potentially represent an underlying central or peripheral nervous system viral infection [7]. The exclusion of the central or peripheral origin of the symptoms required a long time and numerous diagnostic tests before being reached.

Notably, during the last neurological and psychiatric examination, the patient recalled how she had previously experienced similar sensations while rock climbing. Specifically, she recounted how she felt fear and froze midway through her climb as her legs began to tremble and shake. This recollection highlighted the functional origin of the movement symptom-expression of the inability of the subject to communicate her fear using the "word" and not the "body." Indeed, she reported a marked rapid increase of tremor and abnormal movements when she was discharged from the hospital. At the same time, she was still self-isolated, and the two housemates subsequently tested negative to SARS-CoV-2. Tremor and movement disorders were due to COVID-19 fear and the ensuing isolation. Therefore, both these elements should be considered when assisting individuals with SARSCoV-2.

Furthermore, as described in our case study and in a recent report [8], trauma arises from either with the COVID-19 condition itself or with the effects of isolation due to lockdown. The manifestation of the trauma that occurs on the body (i.e., tremor and movement disorders) through defense mechanisms and the recall of different biographical history resemble psychogenic non-epileptic seizures [9]. The time of isolation, not surprisingly, is described as the moment of re-emergence of a dependence or a contact with one's internal world that is difficult to elaborate and may induce dissociative mechanisms [10].

Therefore, this case does not present itself as an example of post-traumatic stress disorder, nor can it be categorized as a psychogenic non-epileptic seizure; it represents the development of psychiatric comorbidity (a functional movement disorder) subsequent to an event threatening bodily integrity and autonomy (i.e., existential continuum) of the subject [11].

\section{Compliance with ethical standards}

Conflict of interest The authors declare that they have no conflict of interest.
Ethical approval All procedures performed in this study were in accordance with the ethical standards of the institutional and national research committee and with the 1964 Helsinki Declaration and its later amendments or comparable ethical standards.

\section{References}

1. Hao F, Tan W, Jiang L, Zhang L, Zhao X, Zou Y, Hu Y, Luo X, Jiang X, McIntyre RS, Tran B, Sun J, Zhang Z, Ho R, Ho C, Tam W (2020) Do psychiatric patients experience more psychiatric symptoms during COVID-19 pandemic and lockdown? A casecontrol study with service and research implications for immunopsychiatry. Brain Behav Immunol 1591(20):3062630627. https://doi.org/10.1016/j.bbi.2020.04.069

2. Valdés-Florido MJ, López-Díaz Á, Palermo-Zeballos FJ, MartínezMolina I, Martín-Gil VE, Crespo-Facorro B, Ruiz-Veguilla M (2020) Reactive psychoses in the context of the COVID-19 pandemic: clinical perspectives from a case series. Rev Psiquiatr Salud Ment (20):30034-30033. https://doi.org/10.1016/j.rpsm.2020.04. 009

3. Shigemura J, Ursano RJ, Morganstein JC, Kurosawa M, Benedek DM (2020) Public responses to the novel 2019 coronavirus (2019$\mathrm{nCoV}$ ) in Japan: mental health consequences and target populations. Psychiatry Clin Neurosci 74:281-282. https://doi.org/10. $1111 /$ pcn. 12988

4. Peckham EL, Hallett M (2009) Psychogenic movement disorders. Neurol Clin 27(3):801-819. https://doi.org/10.1016/j.ncl.2009.04. 008

5. Deuschl G, Köster B, Lücking CH, Scheidt C (1998) Diagnostic and pathophysiological aspects of psychogenic tremors. Mov Disord 13(2):294-302. https://doi.org/10.1002/mds.870130216

6. Baizabal-Carvallo JF, Alonso-Juarez M, Jankovic J (2020) Functional gait disorders, clinical phenomenology, and classification. Neurol Sci 41:911-915. https://doi.org/10.1007/s10072-01904185-8

7. Iroegbu JD, Ifenatuoha CW, Ijomone OM (2020) Potential neurological impact of coronaviruses: implications for the novel SARSCoV-2. Neurol Sci 41:1329-1337. https://doi.org/10.1007/s10072020-04469-4

8. Serafim AP, Gonçalves PD, Rocca CC, Lotufo Neto F (2020) The impact of COVID-19 on Brazilian mental health through vicarious traumatization. Braz J Psychiatry S1516. https://doi.org/10.1590/ 1516-4446-2020-0999

9. Beghi M, Cornaggia I, Magaudda A, Perin C, Peroni F, Cornaggia CM (2015) Childhood trauma and psychogenic nonepileptic seizures: a review of findings with speculations on the underlying mechanisms. Epilepsy Behav 52:169-173. https://doi.org/10. 1016/j.yebeh.2015.09.007

10. van der Hart O, Nijenhuis ERS, Steele K (2006) The haunted self: structural dissociation and the treatment of chronic traumatization. WW Norton \& Company, New York

11. Cerri CG, Perin C, Cornaggia CM, Beghi M (2020) Is posttraumatic stress disorder a too underestimated factor in the early rehabilitation of cerebro-vascular events? Neurol Sci 41(5):12871288. https://doi.org/10.1007/s10072-019-04166-x

Publisher's note Springer Nature remains neutral with regard to jurisdictional claims in published maps and institutional affiliations. 